\title{
CLINICAL EVALUATION OF POST TOTAL HIP / KNEE REPLACEMENT IN HIP / KNEE SPINE SYNDROME
}

\author{
Achmad Fachrizal ${ }^{1}$, Komang Agung Irianto ${ }^{2 *}$ \\ ${ }^{1}$ Resident of Department of Orthopaedic and Traumatology, Faculty of Medicine, Universitas \\ Airlangga, Dr Soetomo Hospital, Surabaya \\ ${ }^{2}$ Staff of Department of Orthopaedic and Traumatology, Faculty of Medicine, Universitas \\ Airlangga, Dr Soetomo Hospital, Surabaya \\ *Correspondence: Komang Agung Irianto, Staff of Department of Orthopaedic and \\ Traumatology, Faculty of Medicine, Universitas Airlangga, Dr Soetomo Hospital, Jl. Mayjen \\ Prof. Dr. Moestopo 6-8, Surabaya 60286 \\ E-mail: komang168@gmail.com
}

\begin{abstract}
ABSTRAK
Insiden osteoarthritis pada hip joint, osteoarthritis pada knee joint, dan degenerative lumbar spondylosis semakin meningkat seiring dengan bertambahnya populasi penduduk usia tua. Kasus Hip/Knee Spine syndrome sendiri cukup sering ditemukan. Namun literatur yang mengevaluasi kondisi klinis, khususnya keluhan low back pain pada pasien dengan hip/knee spine syndrome post total hip/knee replacement masih sangat terbatas Tujuan dari penelitian ini adalah untuk mengevaluasi efek dari total hip/knee replacement pada pasien dengan hip/knee spine syndrome, berkaitan dengan keluhan low back pain.

Penelitian ini adalah observasional retrospektif. Penelitian ini menggunakan 5 orang pasien post total hip/knee replacement yang juga didapatkan keluhan low back pain. Pasien yang terpilih akan dievaluasi klinis dengan menggunakan kuesioner LBP VAS Score, Oswestry Disability Index, Hip Harris Score untuk pasien post total hip replacement, dan Oxford Knee Score untuk pasien post total knee replacement. Dilakukan pengamatan pre dan post operasi pada seluruh pasien. Data pasien didapatkan dari Rumah Sakit Orthopaedi dan Traumatologi Surabaya mulai bulan Juni-November 2015.

Berdasarkan test paired samples, didapatkan hasil sig $0,001(<0,05)$ pada skor VAS dan sig 0,033 $(<0,05)$ pada skor ODI. Maka dapat disimpulkan bahwa terdapat perbedaan yang signifikan antara skor VAS LBP dan skor ODI sebelum dan setelah terapi Hip/Knee Replacement pada pasien dengan Hip/Knee Spine Syndrome.
\end{abstract}

Kata kunci: hip/knee, spine syndrome, skor VAS, skor ODI.

\begin{abstract}
The incidence of osteoarthritis in the hip joint, osteoarthritis of the knee joint, and degenerative lumbar spondylosis is increasing with the aging population. Cases of Hip / Knee Spine syndrome itself are quite often found. However, the literatures that evaluate clinical conditions, especially complaints of low back pain in patients with hip / knee spine syndrome post total hip / knee replacement are still very limited. The purpose of this study is to evaluate the effects of total hip / knee replacement in patients with hip / knee spine syndrome, related to complaints of low back pain.

This research is a retrospective observational study. This study used 5 post hip / knee replacement patients who also received complaints of low back pain. Selected patients will be evaluated clinically using the LBP VAS Score questionnaire, Oswestry Disability Index, Hip Harris Score for post total hip replacement patients, and Oxford Knee Score for post total knee replacement patients. Pre and postoperative observations were made in all patients.
\end{abstract}


Patient data were obtained from the Orthopedic and Traumatology Hospital in Surabaya from June-November 2015.

Based on paired samples test, sig results obtained $0.001(<0.05)$ on the VAS score and sig $0.033(<0.05)$ on the ODI score. It can be concluded that there is a significant difference between LBP VAS scores and ODI scores before and after Hip / Knee Replacement therapy in patients with Hip / Knee Spine Syndrome.

Keywords: hip/knee, spine syndrome, VAS score, ODI score

\section{PENDAHULUAN}

Insiden osteoarthritis pada hip joint, osteoarthritis pada knee joint, dan degenerative lumbar spondylosis semakin meningkat seiring dengan bertambahnya populasi penduduk usia tua.

Istilah Hip spine syndrome pertama kali digunakan oleh Offierski dan MacNab pada tahun 1983 untuk menggambarkan pasien dengan osteoarthritis hip dan lumbar spine disorder. (Offierski, 1983) Sedangkan istilah Knee Spine syndrome merupakan kumpulan gejala yang timbul pada tulang belakang diakibatkan oleh perubahan degeneratif pada lutut. (Murata et al, 2003).

Kasus hip/knee spine syndrome sendiri cukup sering ditemukan pada praktek sehari-hari. Pasien datang dengan keluhan yang bervariasi, antara lain radiating pain pada ekstremitas bawah, berjalan pincang, nyeri pada punggung bawah, nyeri pada pangkal paha dan pantat, dan nyeri pada lutut. Total hip/knee replacement selain dapat menyembuhkan keluhan pada hip/knee, dikatakan juga dapat mengurangi keluhan low back pain pada kasus hip/knee spine syndrome.

Namun literaur yang mengevaluasi kondisi klinis, khususnya keluhan low back pain pada pasien dengan hip/knee spine syndrome post total hip/knee replacement masih sangat terbatas. Sehingga perlu adanya suatu penelitian retrospektif untuk mengevaluasi efek dari total hip/knee replacement pada pasien dengan hip/knee spine syndrome, berkaitan dengan keluhan low back pain.

\section{METODOLOGI PENELITIAN}

Penelitian ini menggunakan rancangan penelitian studi retroprospektif. Penelitian ini menggunakan pasien post total hip/knee replacement yang juga didapatkan keluhan low back pain. Pasien yang terpilih akan dievaluasi klinis dengan menggunakan kuesioner LBP VAS Score (Ogon et al, 1996), Oswestry Disability Index (Fairbank \& Pynsent, 2000), Hip Harris Score untuk pasien post total hip replacement (Soderman \& Malchau, 2001), dan Oxford Knee Score untuk 
pasien post total knee replacement (Jenny

\& Diesinger, 2001). Setiap pasien akan dievaluasi kondisi klinis pre dan post total hip/knee replacement. Sehingga peneliti dapat membandingkan pengaruh total hip/knee replacement pada kasus hip/knee spine syndrome.

Populasi dalam penelitian ini adalah pasien post total hip/knee replacement dengan keluhan low back pain. Sampel yang digunakan adalah pasien post total hip/knee replacement dengan keluhan low back pain serta bersedia menjadi subyek penelitian dan memenuhi kriteria inklusi. Kriteria inklusi pada penelitian ini adalah pasien post total hip/knee replacement dengan keluhan low back pain (minimal 3 bulan post operasi) dan pasien yang bersedia menjadi subyek penelitian. Sedangkan kriteria eksklusi dalam penelitian ini adalah diluar kriteria inklusi yang telah disebutkan di atas.

Teknik pengambilan sampel dilakukan dengan mengambil data pasien post total hip/knee replacement di Rumah Sakit Orthopaedi dan Traumatologi di kota
Surabaya. Selanjutnya identifikasi pasien yang disertai keluhan low back pain. Penelitian ini dilakukan di Rumah Sakit Orthopaedi dan Traumatologi Surabaya. Penelitian ini membutuhkan waktu 6 bulan mulai bulan Juni-November 2015.

\section{HASIL DAN PEMBAHASAN}

Selama kurun waktu tersebut terdapat total 5 pasien Hip/Knee Spine Syndrome yang telah dilakukan Total Hip/Knee Replacement di Rumah Sakit Orthopaedi dan Traumatologi Surabaya, dimana 4 pasien (80\%) adalah wanita dan 1 pasien (20\%) adalah laki-laki dengan distribusi jumlah pasien berdasarkan usia sebagai berikut: usia 50-59 sebanyak 0 pasien (0\%), usia 60-69 sebanyak 2 pasien (40\%), usia 70-79 sebanyak 2 pasien (40\%), usia 80-89 sebanyak 1 pasien $(20 \%)$.

Distribusi pasien hip/knee spine syndrome yang dilakukan terapi hip/knee replacement berdasarkan VAS low back pain pre op dapat dilihat pada Tabel 1 berikut. 
Tabel 1. Distribusi pasien hip/knee spine syndrome yang dilakukan terapi hip/knee replacement berdasarkan VAS low back pain pre op

\begin{tabular}{lll}
\hline VAS Pre & Jumlah & $\begin{array}{l}\text { Persentase } \\
(\boldsymbol{\%})\end{array}$ \\
\hline $\boldsymbol{O p}$ & & $20 \%$ \\
\hline Mild & 1 & $80 \%$ \\
Moderate & 4 & $0 \%$ \\
Severe & 0 & 0 \\
\hline
\end{tabular}

Distribusi pasien hip/knee spine replacement berdasarkan VAS low back syndrome yang dilakukan terapi hip/knee pain pre op dapat dilihat pada Tabel 2.

Tabel 2. Distribusi pasien hip/knee spine syndrome yang dilakukan terapi hip/knee

\begin{tabular}{|c|c|c|c|c|}
\hline $\begin{array}{l}\text { VAS Pre } \\
\text { Op }\end{array}$ & Jumlah & Membaik & Memburuk & $\begin{array}{l}\text { Persentase } \\
(\%)\end{array}$ \\
\hline Mild & 1 & 1 & 0 & $100 \%$ \\
\hline Moderate & 4 & 4 & 0 & $100 \%$ \\
\hline Severe & 0 & 0 & 0 & $0 \%$ \\
\hline
\end{tabular}

Distribusi pasien hip/knee spine Disability Index) pre op dapat dilihat pada syndrome yang dilakukan terapi hip/knee Tabel 3 berikut. replacement berdasarkan ODI (Oswestry

Tabel 3. Distribusi pasien hip/knee spine syndrome yang dilakukan terapi hip/knee replacement berdasarkan ODI (Oswestry Disability Index) pre op

\begin{tabular}{lcc}
\hline ODI Awal & Jumlah & $\begin{array}{l}\text { Persentase } \\
(\boldsymbol{\%})\end{array}$ \\
\hline $\begin{array}{l}\text { Disabilitas } \\
\text { minimal }\end{array}$ & 3 & $60 \%$ \\
$\begin{array}{l}\text { Disabilitas } \\
\text { sedang }\end{array}$ & 1 & $20 \%$ \\
$\begin{array}{l}\text { Disabilitas } \\
\text { berat }\end{array}$ & 1 & $20 \%$ \\
$\begin{array}{l}\text { Lumpuh } \\
\text { Ambulatoir }\end{array}$ & 0 & $0 \%$ \\
\hline
\end{tabular}

Sedangkan distribusi pasien ODI (Oswestry Disability Index) post op hip/knee spine syndrome yang dilakukan dapat dilihat pada Tabel 4 berikut. terapi hip/knee replacement berdasarkan 
Tabel 4. Distribusi pasien hip/knee spine syndrome yang dilakukan terapi hip/knee replacement berdasarkan ODI (Oswestry Disability Index) post op

\begin{tabular}{lcccc}
\hline ODI Awal & Jumlah & Membaik & Memburuk & $\begin{array}{l}\text { Persentase } \\
(\%)\end{array}$ \\
\hline $\begin{array}{l}\text { Disabilitas } \\
\text { minimal }\end{array}$ & 1 & 1 & 0 & $100 \%$ \\
$\begin{array}{l}\text { Disabilitas } \\
\text { sedang }\end{array}$ & 3 & 3 & 0 & $100 \%$ \\
$\begin{array}{l}\text { Disabilitas } \\
\text { berat }\end{array}$ & 1 & 1 & 0 & $100 \%$ \\
$\begin{array}{l}\text { Lumpuh } \\
\text { Ambulatoir }\end{array}$ & 0 & 0 & 0 & $0 \%$ \\
\hline & 0 & 0 & 0 & $0 \%$ \\
\hline
\end{tabular}

Perbandingan VAS low back pain dan ODI sebelum dan sesudah terapi hip/knee replacement dapat diketahui dengan melakukan uji statistik. Uji normalitas dilakukan pertama kali untuk mengetahui distribusi normalitas data. Uji normalitas yang digunakan yaitu uji Kolmogorov-smirnov. Setelah didapatkan hasil bahwa semua data variabel berdistribusi normal, maka dapat dilakukan uji paired t-test. Hasil uji normalitas dapat dilihat pada Tabel 5.

Tabel 5. Uji Normalitas VAS dan ODI sebelum dan sesudah terapi Hip/Knee Replacement

\begin{tabular}{lc}
\hline VAS Pre Hip/Knee Replacement & 0,577 \\
VAS Post Hip/Knee Replacement & 0,510 \\
$\begin{array}{l}\text { Oswestry LBP Disability Pre } \\
\text { Hip/Knee Replacement }\end{array}$ & 0,690 \\
$\begin{array}{l}\text { Oswestry LBP Disability Post } \\
\text { Hip/Knee Replacement }\end{array}$ & 0,684
\end{tabular}

Selanjutnya dilakukan uji paired Ttest VAS dan ODI sebelum dan sesudah terapi hip/knee replacement sebagaimana tertera pada Tabel 6.

Tabel 6. Hasil uji paired t-test VAS dan ODI sebelum dan sesudah terapi Hip/Knee Replacement

\begin{tabular}{lc}
\hline \multicolumn{1}{c}{ Variabel } & $\begin{array}{c}\mathbf{p} \\
\text { score }\end{array}$ \\
\hline VAS Pre/ Post Hip/Knee Replacement &, 001 \\
$\begin{array}{l}\text { OSWESTRY LBP DISABILITY Pre- } \\
\text { post Hip/Knee Replacement }\end{array}$ &, 033 \\
\hline
\end{tabular}

Dari test paired samples tersebut didapatkan hasil sig $0,001 \quad(<0,05)$ pada skor VAS dan sig 0,033 $(<0,05)$ pada skor ODI. Berdasarkan hasil tersebut dapat disimpulkan bahwa, terdapat perbedaan yang signifikan antara skor VAS LBP dan skor ODI sebelum dan setelah terapi Hip/Knee Replacement pada pasien dengan Hip/Knee Spine Syndrome. 
Dari 5 kasus hip/knee spine syndrome pada penelitian ini, pasien datang dengan keluhan yang bervariasi, antara lain radiating pain pada ekstremitas bawah, berjalan pincang, nyeri pada punggung bawah, nyeri pada pangkal paha dan pantat, dan nyeri pada lutut, sehingga penting untuk menetukan proses patologis yang menyebabkan keluhan pasien. Hal ini sesuai dengan review article tentang HipSpine synndrome oleh Devin et al, 2012. Pasien dengan keluhan nyeri pada daerah ekstremitas bawah dan bukti radiologis adanya Hip/Knee-Spine syndrome harus dilakukan pemeriksaan klinis, yang meliputi anamnesis dan pemeriksaan fisik, termasuk pemeriksaan penunjang yang spesifik untuk mengetahui penyebab primer dari keluhan pasien.

Seperti pada kasus pasien 1 dengan Hip Knee Spine Syndrome + AVN Hip Bilateral Grade IV + OA Knee Sinistra Grade II + Spondylosis Lumbalis + Spondylolithesis L4-5 Grade I + Foramina Stenosis, didapatkan riwayat operasi Laminotomi oleh Bedah Saraf sebelumnya, namun pasien merasakan tidak didapatkan perbaikan pada nyeri. Namun setelah dilakukan total hip replacement, pasien merasakan perbaikan yang signifikan. Dari kasus pasien 1 dapat disimpulkan bahwa penting untuk menentukan dimana proses patologis yang menyebabkan nyeri, apakah pada spine, hip joint, atau knee joint, terutama pada kasus secondary hip/knee spine syndrome atau complex hip/knee spine syndrome yang mana proses proses patologis sulit untuk ditentukan dengan modalitas diagnostik rutin. Didapatkan beberapa modalitas diagnostik lebih lanjut seperti injeksi intraartikuler pada hip/knee joint atau injeksi epidural pada spine dengan fluoroscopy sehingga kita dapat menentukan proses patologis yang menyebabkan nyeri. Dengan mengetahui proses patologis yang dominan menyebabkan nyeri maka kita dapat menentukan pilihan terapi yang sesuai, apakah spine dekompresi atau total hip/knee replacement (Devin et al, 2012). Dari kasus pasien 1, dapat kita simpulkan juga pentingnya komunikasi dokter dan pasien tentang kemungkinan operasi kedua pada kasus hip/knee spine syndrome jika masih didapatkan nyeri yang menetap setelah operasi pertama.

\section{Dari 5 pasien Hip/Knee Spine} Syndrome yang dilakukan Total Hip/Knee Replacement di Rumah Sakit Orthopaedi dan Traumatologi Surabaya, secara statistik didapatkan perbedaan yang signifikan pada skor VAS Low Back Pain 
dan skor Oswestry Disability Index sebelum dan sesudah total hip/knee replacement. Hal ini sesuai dengan Parvizi dan rekan meneliti 344 pasien yang akan menjalani Total Hip Arthroplasty dengan berbagai sebab (326 pasien Osteoarthritis, 9 pasien Displaced Femoral Neck Fracture, 7 pasien Avaskuler nekrosis, dan 2 pasien Developmental Displasia of the Hip). Dari 205 pasien dengan keluhan low back pain, 113 pasien $(66,4 \%)$ mengatakan keluhannya menghilang setelah menjalani operasi THA. Sedangkan dari 57 pasien yang keluhan low back painnya tidak membaik, 37 pasien diketahui memiliki kelainan pada daerah lumbar spine yang memerlukan penanganan lebih lanjut (Parvizi et al, 2010).

\section{KESIMPULAN}

Penelitian retrospektif tentang hip/knee spine syndrome menunjukan hasil:

1. Didapatkan perbaikan pada Visual Analogue Score Low Back Pain pada Pasein Hip/Knee Spine Syndrome setelah dilakukan Hip/Knee Replacement.

2. Didapatkan perbaikan pada Oswestry Low Back Pain Disability pada Pasein Hip/Knee Spine Syndrome setellah dilakukan Hip/Knee Replacement.
3. Pasien dengan keluhan nyeri pada daerah ekstremitas bawah dan bukti radiologis adanya Hip/Knee-Spine syndrome harus dilakukan pemeriksaan klinis, yang meliputi anamnesis dan pemeriksaan fisik, termasuk pemeriksaan penunjang yang spesifik untuk mengetahui penyebab primer dari keluhan pasien.

\section{SARAN}

Penelitian lebih jauh tentang hip/knee spine syndrome diperlukan adanya pencatatan rekam medik yang lengkap VAS dan ODI setiap pasien kontrol untuk mendapatkan hasil penelitian yang lebih komprehensif, diperlukan penelitian multicenter dengan sample yang lebih besar untuk penelitian sejenis selanjutnya dan prosedur tetap penatalaksanaan pasien dengan hip/knee spine syndrome.

\section{REFERENSI}

Devin CJ, McCullough KA, Morris BJ, Yates AJ, Kang JD. Hip-spine Syndrome. J Am Acad Orthop Surg [Internet]. 2012;20(7):434-42.

Fairbank JCTMDF, Pynsent PBP. The Oswestry Disability Index. Spine. 2000. p. 2940-53.

Jenny JY, Diesinger Y. The Oxford Knee Score: Compared performance before and after knee replacement. Orthop Traumatol Surg Res 
[Internet]. Elsevier Masson SAS;

2012;98(4):409-12.

Murata Y, Takahashi K, Yamagata M, Hanaoka E, Moriya H. The kneespine syndrome. J Bone Jt Surg [Internet]. 2003;85(1):95-9.

Offierski CM. Hip-spine syndrome. Spine (Phila Pa 1976). 1983 Apr;8(3):31621. 1983. p. 316-21.

Ogon M, Krismer M, Söllner W, KantnerRumplmair W, Lampe A. Chronic low back pain measurement with visual analogue scales in different settings [Internet]. Pain. 1996. p. 425-8.

Parvizi J, Pour AE, Hillibrand A, Goldberg G, Sharkey PF, Rothman RH. Back pain and total hip arthroplasty: A prospective natural history study. Clin Orthop Relat Res. 2010;468(5):1325-30.

Söderman P, Malchau H. Is the Harris hip score system useful to study the outcome of total hip replacement? Clinical orthopaedics and related research. 2001. p. 189-97. 